\title{
Immortality of the Soul as an Intuitive Idea: Towards a Psychological Explanation of the Origins of Afterlife Beliefs
}

\author{
Vera Pereira ${ }^{\mathrm{a}, *}$, Luís Faísca ${ }^{\mathrm{b}}$ and Rodrigo de Sá-Saraiva ${ }^{\mathrm{a}}$ \\ ${ }^{\text {a }}$ Faculdade de Psicologia, Universidade de Lisboa, Alameda da Universidade, \\ 1649-013 Lisboa, Portugal \\ b IBB/CBME, Faculdade de Ciências Sociais e Humanas, Universidade do Algarve, \\ 8005-139, Faro, Portugal \\ * Corresponding author, e-mail: verapereira@campus.ul.pt
}

\begin{abstract}
This study tried to investigate if intuitive ideas about the continuation of the Self after death determine the way people represent the state of being dead, and, in this way, investigate possible psychological origins of afterlife beliefs, which constitute a recurrent cultural phenomenon. A semi-structured interview and a self-report questionnaire were used to obtain information on the experience of imagining oneself as dead and the representation of the dead-I of young adults. The results suggest that (1) there is a tendency to imagine the state of being dead as a continuation of the I, even in the absence of explicit afterlife beliefs; (2) perceptual, emotional, epistemic and desire experiences are associated to the dead-I; (3) the representation of the dead-I seems to be determined by an interaction between cognitive processes related to self-awareness and theory of mind, and the cultural afterlife beliefs explicitly learned. A previous alternative hypothesis, suggesting that simulation constraints were responsible for the emergence of non-reflective afterlife concepts (Bering, 2002, 2006) is not completely supported by our results. The data presented here suggest that immortality of the soul might be an intuitive religious concept, connected to the experience of the Self and to the implicit theorization that the experienced Self is independent from the body. Future studies should focus on the collection of cross-cultural and developmental data.
\end{abstract}

\section{Keywords}

Death, afterlife beliefs, I, self-awareness, Theory of Mind

The last decades have witnessed a revision of cultural relativism and an increasing amount of interest in the identification of universal cognitive mechanisms responsible for inter-culture similarities (Brown, 1991; Pinker, 2002). Recent reviews of the concept of Culture, made by anthropologists like Boyer (1994), Brown (1991) or Sperber (1996), stressed the importance of the identification 
of recurrent cultural elements in the investigation of cognitive mechanisms typical of the human species.

Beliefs in afterlife are a recurrent and prevalent characteristic of Human Culture, since they seem to be an essential element of religious thought in all known human cultures (Morin, 1970; Thomas, 1976; Obayashi, 1992). Birket-Smith (1955) ventured that the only cultures that do not show afterlife beliefs are those in which those beliefs were not researched. This inter-cultural recurrence and prevalence over time may be a sign that humans have an intuitive tendency to understand death as the continuity of existence.

The natural or cognitive origins of afterlife beliefs (AB) have recently been explored through studies centered in the representation of dead agents (Bering, 2002, 2006; Bering and Bjorklund, 2004; Bering et al., 2005). Assuming a simulational account of the theory of mind (Goldman, 1992, 1993; Harris, 1992), according to which the inference of internal states of other agents is made using our own experiences as a reference, Bering (2002) predicted that when we try to imagine what it would be like to be dead, we would try to imagine what it is like to "be an agent that is dead" through the same simulational mechanisms we use in our daily lives to predict and explain the behaviour of social agents. Death is an unknown experience for everyone, and because of that, the reliance on our introspection to imagine what a dead agent might be is a problem, since we have no personal information on which we can rely.

It follows that while trying to imagine the total lack of physical and mental states that death supposedly is, we would be confronted with two distinct kinds of states: those the absence of which is very easy to imagine (EIA), because we have experienced it on our daily lives, and those the absence of which is difficult to imagine (DIA), since we never or only rarely experience their absence. Examples of DIA states are epistemic (thought), emotional (fear, joy), and desire (will) experiences. Examples of EIA states are biological (eating, drinking), psychobiological (hunger, sexual desire) and perceptive (seeing, hearing) experiences.

According to this idea, the dead agents should be imagined as experiencing mainly those states the absence of which is more difficult to imagine. With this simulation constraint hypothesis in mind, Bering (2002) conducted a study in which he told a story of an imaginary agent who had died. After reading the story, the participants were asked to judge whether Biological, Psychobiological, Perceptive, Emotional, Desire and Epistemic states continued after the death of the agent. A response was coded as continuity reasoning if the biological or mental state was considered to function despite the agent's death; discontinuity reasoning code was used when participants judged the biological or mental state as ceasing to exist as a result of death. 
The author verified that the emotional, desire and epistemic states were the ones more frequently attributed to the dead agent. He found that the same pattern occurred for different types of $\mathrm{AB}$ and that even participants that did not believe in any form of afterlife (extinctivists) gave a superior amount of continuity reasoning responses to epistemic states than the rest of the sample.

Despite this general pattern of responses, the $A B$ type had some effect on the answers, since participants that stated they believed in reincarnation had the higher number of continuity reasoning responses, while those who classified themselves as extinctivists were the ones who gave less continuity responses. For Bering (2002), this result indicates that subject's responses express an interaction between their culturally acquired $A B$ and their intuitive notion of what might be the internal states of dead agents.

Pyysiäinen (2003) criticizes the simulation constraint hypothesis, since there is no empirical evidence sustaining differences in the difficulty to imagine the absence of mental states. He claims that the absence and cessation of certain emotional and desire states is frequent, e.g., the experience of absence of the will to do something. This author suggests that an alternative hypothesis to Bering's simulation constraint hypothesis might be the degree in which experiences are usually perceived as dependent on the body. Pyysiäinen (2003) proposes that while thinking about dead agents people focus on the types of experiences they could continue to have without a body.

The notion that we are "common sense dualists" condemned to believe in God and the afterlife (Bloom, 2004, 2007) is compatible with the ideas of authors (Bauman, 1992; Freud, 1915/1957; Sá-Nogueira Saraiva, 2003) that suggested that it is impossible for human beings to imagine the complete death of themselves, even if the end of their body is easily conceivable. This impossibility may result from the phenomenological tendency in humans to imagine their own deaths from the perspective of a spectator: "It is indeed impossible to imagine our own death; and whenever we attempt to do so we can perceive that we are in fact still present as spectators" (Freud, 1915/1957, p. 289).

Sá-Nogueira Saraiva (2003) proposes that the afterlife beliefs are a consequence of the human capacity to experience the Self simultaneously as a subject and an object. These two modalities of self-awareness have been identified and described in psychological literature by a myriad of authors (James, 1890; Duval and Wicklund, 1972; Damásio, 2010), all of them emphasizing the difference between the awareness of Self as a subject of experience, an agent in the world, and as an object possible to be examined from a distant perspective.

Sá-Nogueira Saraiva (2003) denominates the experience of the Self as a subject as Subject-Self and the experience of the Self as an object as ObjectSelf. The Subject-Self corresponds to the centre of agency and representation 
of the world to which we usually call "I", and is felt as independent on the body. Strawson (2009) refers to it as "self-experience" which corresponds to the sensation of being a cohesive, continuous, internal/mental subject of experience, that is aware of itself, has emotions, thoughts and intentions and a certain personality. Sá-Nogueira Saraiva's (2003) Object-Self, or "Me" in James's (1890) terminology, corresponds to the image we create of ourselves and is associated with the body and other public aspects of the Self, such as physical appearance.

According to Sá-Nogueira Saraiva (2003), the duality between Subject-Self (I) and Object-Self (Me) inevitably emerges when we try to imagine our own death: it appears in our imagination as the death of an object - ourselves - that is observed by a subject - ourselves as well. This cognitive incapacity to eliminate the Self as the subject of experience would constitute the psychological basis for the emergence of intuitive notions about the continuation of a part of the Self after death, expressed in the cultural recurrent beliefs related to the immortality of the soul (Eliade, 1951/1968; Morin, 1970).

In this study, we propose to investigate if there is a tendency to imagine death as a state of continuation of the I or Subject-Self (Sá-Nogueira Saraiva, 2003), and to understand the cognitive mechanisms responsible for the way in which people implicitly represent their dead-I. Specifically, we intend to clarify if representations of the dead-I are determined by the simulation constraint proposed by Bering (2002), by an implicit theory about the degree of body dependence of various mental states (Pyysiäinen, 2003), and/or by the assumption of continuity of the I (or Subject-Self) with the same characteristics that are associated to it in life (Sá-Nogueira Saraiva, 2003). The hypothesis of Sá-Nogueira Saraiva (2003) and Pyysiäinen (2003) are compatible, since both assume that the characteristics associated to the dead-I are those perceived as somehow independent on the body. The proposals of Bering (2002) and Sá-Nogueira Saraiva (2003) also have contact points, since both authors presume a cognitive constraint that prevents us from imagining the end of all types of experience. The difference lies in the fact that Sá-Nogueira Saraiva (2003) considers the importance of the phenomenological experience of being an I or Subject-Self, while Bering (2002) centres his proposal in the functioning of our simulational abilities, without reference to the "Selfexperience" (Strawson, 2009).

If Sá-Nogueira Saraiva (2003) is correct, and the phenomenological experience of the I affects the way people represent their own deaths, it is expected that the dead-I is represented in the same way as the I experienced in life, and that it might have, besides emotional, epistemic and desire states, also perceptive ones, because the self-experience is usually associated with mental images. Since the I is implicitly conceived as independent on the body (Sá-Nogueira 
Saraiva, 2003), the degree in which a mental state is perceived as body dependent could also determine if it would be attributed to the dead-I. This last prediction is also in accordance with the proposal of Pyysiäinen (2003).

If Bering's $(2002,2006)$ proposal applies to the representation of one's own death, it is expected that epistemic, emotional and desire states should be attributed to the dead-I in superior proportion to perceptive and psychobiological states, independently of the degree in which they are perceived as body dependent.

An additional objective of this study is to understand how explicit cultural beliefs about afterlife influence the implicit representations of the dead-I.

\section{Method}

\section{Participants}

Research participants were 40 young adults, half of each sex between 20 and 30 years of age (mean \pm SD $24.98 \pm 2.30$ years), living in Lisbon, $75 \%$ of which are recent graduates and $25 \%$ are undergraduate students, of various courses. Participants were recruited by email. They were asked to participate in a study in which they would have to talk about personal feelings and thoughts about their own death. Most of the sample (57.5\%) has experienced the death of someone close in less than 5 years, which might be a sign that mourning is a common experience in this age range. The religious background of the sample is mainly Catholic, but only 5\% of participants still consider themselves as Catholic. Only 30\% of the sample believes in God or other supernatural force/ being. Participants who had a suicidal history, a chronic or terminal disease or relatives with terminal disease where excluded from the sample.

\section{Procedure}

Having in mind the exploratory nature of this study, a semi-structured interview was chosen as the data gathering technique, since it was considered that the specific questions necessary to collect the desired information might vary in each interview, according to different interviewer-interviewee dynamics (Pollio et al., 1997/2006). The semi-structured interviews were based on a script (see Appendix A) that prescribed the themes to explore and some possible relevant questions, without imposing a rigid order of questions. It was assumed that the interviewer might improvise to match the rhythm of each interview (Mason, 1998).

A questionnaire, specifically constructed to collect information about the degree of body dependence attributed to various kinds of experiences, was also 
presented during the interview. This questionnaire includes 25 items representative of psychobiological, perceptual, epistemic, emotional and desire experiences (see Appendix B).

Before initiating the interview, the participants were told that we were interested in their personal perspective and that there were no right or wrong answers. We asked permission to record the interview (confidentiality and anonymity being assured).

After some ice-breaking questions, participants were asked to "concentrate, close their eyes for some seconds and try to imagine what it is like to die and be dead". Participants were then told to report what they thought during the exercise. If the answers did not refer to the dead-I (e.g., just saying "everything dark", or "people crying"), additional questions were asked to try to get information about the represented dead-I: "If you had to imagine yourself in a life after death, independently of what you believe will happen after death, how would you be like?"

After the implicit representation of the dead-I had been clarified through questions about the different kinds of experience it might continue to have, the Degree of Body Dependence (DBD) Questionnaire was presented. Using a four-point scale (ranging from "Totally independent on the body" to "Totally dependent on the body"), participants were asked to evaluate the degree in which they felt that each experience listed in the questionnaire is dependent on the body. They were instructed to base their evaluations on what they feel in their daily lives and not on their scientific knowledge. Participants were further asked to indicate, based on the imagination exercise conducted earlier, which of the 25 experiences listed in the DBD Questionnaire might continue after death.

At the end of the interview, we collected information about the explicit beliefs in afterlife of the participants, as well as their religious beliefs: "Do you believe in any form of afterlife?", "Do you consider yourself a religious person?", "What is your religious belief?"

These questions were left to the end of the interview to prevent contamination of the answers by the explicit beliefs in afterlife.

\section{Results}

This study had a mixed methods design, using a semi-structured interview that was complemented with a quantitative instrument, the DBD Questionnaire. We will first present the results obtained from the analysis of the interview data, and then the results obtained with the questionnaire. 


\section{Qualitative data analysis}

We used NVivo 7 software and adopted a simultaneous bottom-up and top-down procedure to analyze the data collected in the interview, following the guidelines suggested by Miles and Huberman (2004). The main categories (tree-nodes) were defined a priori and correspond to the three themes of the interview script (Experience of imagination of one's own death, Implicit representation of the dead-I and Explicit beliefs in the afterlife). Subcategories (child-nodes) were based on patterns that emerged from the data (see Appendix $\mathrm{C}$ for examples of responses coded in the nodes presented in this section).

Table 1 presents the types of $\mathrm{AB}$ identified in the sample, that correspond to the child-nodes inside the Explicit beliefs in the afterlife tree-node.

\section{Table 1}

Explicit Beliefs in the Afterlife - Child-Nodes and their Operational Definition

\begin{tabular}{l}
$\begin{array}{l}\text { Types of explicit } \\
\text { beliefs in afterlife }\end{array} \quad$ Operational definition of the node $\begin{array}{c}\text { No. of participants } \\
\text { coded in each } \\
\text { child-node }(\%)\end{array}$ \\
\hline
\end{tabular}

Non-belief in the Lack of any kind of belief in an afterlife.

$23(57.5 \%)$ afterlife

Afterlife possible Life after death is considered possible, but uncertain psychologically plausible and desirable, but there is uncertainty about its existence. Afterlife is seen as a continuation of the I, that would maintain consciousness of itself and a significant part of the mental capacities held in life (e.g., memory and thought).

Afterlife in After death, the I continues to exist outside another the Earth, in another dimension, keeping the dimension same psychological traits and the memories of the previous life. Interaction with other selves is usually possible in that other dimension, which is compared to the Christian Heaven.
Afterlife
A part of the person continues to exist after without an I death without a center of consciousness, or I (Self), that is aware of itself and exists as a bounded entity.
Afterlife Belief in afterlife accompanied by uncertainty undefined about how and what that afterlife might be. 
Most of the participants are non-believers in afterlife (57.5\%). Almost all the other types of $\mathrm{AB}$ identified seem to assume the continuation of the $\mathrm{I}$ in an afterlife.

The type of afterlife belief does not vary according to $\operatorname{sex}\left(\chi^{2}=0.102, \mathrm{df}=1\right.$, $p=0.794)$ but seems to be associated with age $\left(\chi^{2}=5.013, \mathrm{df}=1, p=0.025\right)$, since $60 \%$ of the participants aged between 26 and 30 years believe in some kind of afterlife and only $25 \%$ in the range between 20 and 25 years do not show any kind of belief.

Table 2 presents the child-nodes created to code the responses to the imagination exercise proposed in the beginning of the interview. A non-exclusive codification was used for these nodes and the same participant can be associated to several categories.

The majority of the sample (75\%) has imagined the state of being dead as a state where self-experience continues present. Almost half of the participants (42.5\%) reported the sensation of imagining death in the perspective of a spectator. Only one participant focused in the moment that anticipates death.

The tree-node Implicit representation of the Dead-I includes two subcategories - Types of representation of the dead-I and Experiences of the dead-I -, each of them with several child-nodes. Table 3 presents the different Types of representation of the dead-I.

The participants showed a tendency to represent the dead-I as similar to the I experienced in life ( $87.5 \%$ of the sample).

Table 4 presents the child-nodes of Experiences of the dead-I, created to code the answers about the types of experiences that the dead-I can have. Again, a non-exclusive codification was used for these nodes.

The results showed that the experiences mostly associated to the dead-I were Perceptual (82.5\%), Epistemic (67.5\%) and Emotional (40\%). The perceptual experiences most attributed to the dead-I were Vision $(77.5 \%)$ and Hearing (35\%). In the Epistemic node, the experiences mostly associated with the dead-I were Consciousness (45\%), Memory (37.5\%) and Thought (30\%). A slight percentage of the sample $(17.5 \%)$ has attributed to the dead-I the capacity to move.

\section{Relationship Between the Type of Explicit Belief in Afterlife and the Other Nodes}

In order to understand if different $\mathrm{AB}$ are associated with different kinds of imagination experiences and representations of the dead-I, the NVivo7 Matrix coding query option was used to explore the relation between the different tree nodes. 
Table 2

Experience of Imagination of One's Own Death-Child-Nodes and their Operational Definition

\begin{tabular}{|c|c|c|}
\hline $\begin{array}{l}\text { Types of Experience } \\
\text { of imagination of } \\
\text { one's own death }\end{array}$ & Operational definition of the node & $\begin{array}{l}\text { No. of } \\
\text { participants } \\
\text { coded in each } \\
\text { child-node }(\%)\end{array}$ \\
\hline $\begin{array}{l}\text { Continuation of the } \\
\text { I }\end{array}$ & $\begin{array}{l}\text { The state of being dead is imagined as a state } \\
\text { in which the I, but not the body, continues } \\
\text { to exist, in the form of psychological activity } \\
\text { such as consciousness, memory and even } \\
\text { perceptual abilities, like vision. }\end{array}$ & $30(75.0 \%)$ \\
\hline $\begin{array}{l}\text { Observation of one's } \\
\text { own death }\end{array}$ & $\begin{array}{l}\text { During the imagination exercise there is the } \\
\text { feeling of being the observer of one's own } \\
\text { death and not an active participant in it. The } \\
\text { state of being dead is imagined in the } \\
\text { perspective of a spectator that witnesses the } \\
\text { death of the body, as if it belonged to } \\
\text { another being. }\end{array}$ & $17(42.5 \%)$ \\
\hline $\begin{array}{l}\text { The I that continues } \\
\text { is connected do the } \\
\text { body }\end{array}$ & $\begin{array}{l}\text { Death is imagined as a state of continuation } \\
\text { of the I, which remains physically close to } \\
\text { the body (in some cases inside the coffin), as } \\
\text { if it were still connected to the body. }\end{array}$ & $11(27.5 \%)$ \\
\hline $\begin{array}{l}\text { Impossibility of } \\
\text { imagining death as a } \\
\text { total end }\end{array}$ & $\begin{array}{l}\text { Imagination exercise is accompanied by the } \\
\text { feeling of being very difficult or even } \\
\text { impossible to imagine death as a total end of } \\
\text { existence. }\end{array}$ & $14(35 \%)$ \\
\hline Absence of the I & $\begin{array}{l}\text { The imagination of death as the definitive } \\
\text { end of existence. The state of being dead is } \\
\text { imagined as the absence of any mental or } \\
\text { bodily activity. The idea of inexistence and } \\
\text { emptiness is also present. }\end{array}$ & $9(22.5 \%)$ \\
\hline $\begin{array}{l}\text { Imagination of the } \\
\text { moment before } \\
\text { dying }\end{array}$ & $\begin{array}{l}\text { Imagination of the moment just before } \\
\text { death, in which death is already expected } \\
\text { but is not happening yet. }\end{array}$ & $1(2.5 \%)$ \\
\hline
\end{tabular}


Table 3

Types of Representation of the Dead-I - Child-Nodes and their Operational Definition

\begin{tabular}{lc}
\hline $\begin{array}{l}\text { Types of } \\
\text { representation of } \\
\text { the dead-I }\end{array}$ & $\begin{array}{c}\text { No. of } \\
\text { participants } \\
\text { coded in each } \\
\text { child-node (\%) }\end{array}$ \\
\hline
\end{tabular}

Dead-I similar to Dead-I similar to the one held in life, with

$35(87.5 \%)$

the one held in life the same psychological characteristics, the same cognitive and perceptual capacities, memory of past events and awareness of itself. Some answers report also the capability of the dead-I to have the ability to move and touch.

Dead-I distinct from the one held in life
Dead-I is different from the I experienced in life. The awareness of being the same I (Self) as in life is lost, as well as the memories of the life before. Dead-I could be dismantled and only an "essence" of the person continues in another body and another I (Self). The I (Self) loses the status of separation relatively to the world and other Selves, occurring a fusion, with the loss of its frontiers.

Dead-I non-existent With the death of the body, the self is lost. Existence after death could not be imagined.
$3(7.5 \%)$

$2(5.0 \%)$

\begin{abstract}
Among the five types of $\mathrm{AB}$, the experience of Continuation of the I was the most frequent. Even $60.9 \%$ of the non believers reported this kind of experience. Despite this general pattern, explicit $A B$ seem to influence in some degree the experience of imagining one's own death, since only the participants that do not believe in afterlife imagined death as the Absence of the I.

Dead-I similar to the one held in life was the more frequent type of representation in all types of $A B$, with the exception of Afterlife without an I, for which the representation of the Dead-I distinct from the one held in life was equally frequent. The representation of the Dead-I as non-existent was only reported by participants that do not believe in any form of afterlife, but even in that group, only $6.5 \%$ responded in that way.
\end{abstract}


Table 4

Experiences of the Dead-I - Child-Nodes and their Operational Definition

\begin{tabular}{|c|c|c|}
\hline $\begin{array}{l}\text { Types of } \\
\text { experiences of } \\
\text { the dead-I }\end{array}$ & Operational definition of the node & $\begin{array}{l}\text { No. of } \\
\text { participants } \\
\text { coded in each } \\
\text { child-node }(\%)\end{array}$ \\
\hline Psychobiologic & $\begin{array}{l}\text { Internal states connected with physiological } \\
\text { necessities, like feeling hungry, thirsty or feeling } \\
\text { sexually stimulated. }\end{array}$ & $0(0.0 \%)$ \\
\hline Perceptual & $\begin{array}{l}\text { Sensations from of all sensorial modalities, like } \\
\text { vision and olfaction. }\end{array}$ & $33(82.5 \%)$ \\
\hline Emotional & Emotions and feelings. & $16(40.0 \%)$ \\
\hline Epistemic & $\begin{array}{l}\text { Cognitive activity involving thought processes } \\
\text { and memory. }\end{array}$ & $27(67.5 \%)$ \\
\hline Desire & $\begin{array}{l}\text { Internal states connected with desire and } \\
\text { intention. }\end{array}$ & $3(7.5 \%)$ \\
\hline
\end{tabular}

The perceptual, epistemic and emotional experiences were attributed to the dead-I by all types of $\mathrm{AB}$. Concerning the frequency in which the experiences were reported, all types of $\mathrm{AB}$ showed the pattern "perceptual>epistemic> emotional", except for Afterlife undefined (where the pattern was "perceptual> emotional>epistemic") and Afterlife without an I, which did not show differences in the frequency of attribution of various kinds of experiences to the dead-I ("perceptual=epistemic=emotional").

Despite the similarities found, there are differences in the percentage in which each specific experience was attributed by each type of $A B$ to the dead-I. For instance, $78.3 \%$ of Non-believers in an afterlife have considered that the dead-I might have visual experiences, while for the believers in an Afterlife possible but uncertain, Afterlife in another dimension and Afterlife undefined that percentage reached $100 \%$. The percentage of emotional experiences attributed to the dead-I was larger for Afterlife possible but uncertain and Afterlife undefined groups (75 and 66.7\%, respectively), than for nonbelievers in an afterlife (34.7\%) and believers in Afterlife in another dimension (33.3\%). The attribution of epistemic experiences was more frequent for Afterlife possible but uncertain (75\%) and Afterlife in another dimension $(83.3 \%)$ than for the remaining groups. Curiously, non-believers in an afterlife presented a higher percentage of this kind of responses (69.6\%) than the 
group of believers in an Afterlife without an I (25\%) and an Afterlife undefined $(33.3 \%)$.

In general, there seems to be a tendency, not dependent on the explicit beliefs in afterlife, to attribute perceptual, epistemic and emotional experiences to the dead-I. The explicit beliefs can however influence this trend since the belief in any kind of afterlife tends to increase the attribution of experiences to the dead-I, except when those beliefs are contrary to the permanence of the I after death.

\section{Quantitative Data Analysis}

Experiences that Continue and do not Continue after Death. Figure 1 presents the percentage of continuity responses for each of the 25 items of the DBD Questionnaire.

We used the binominal test to identify which of the 25 experiences were evaluated by more than $50 \%$ of the sample as being possible and not possible to continue after death. Results showed that seven experiences were considered by significantly more than $50 \%$ of the participants as possible to continue after death: Concentrating on a subject $(75 \%, p=0.002)$, Being in love

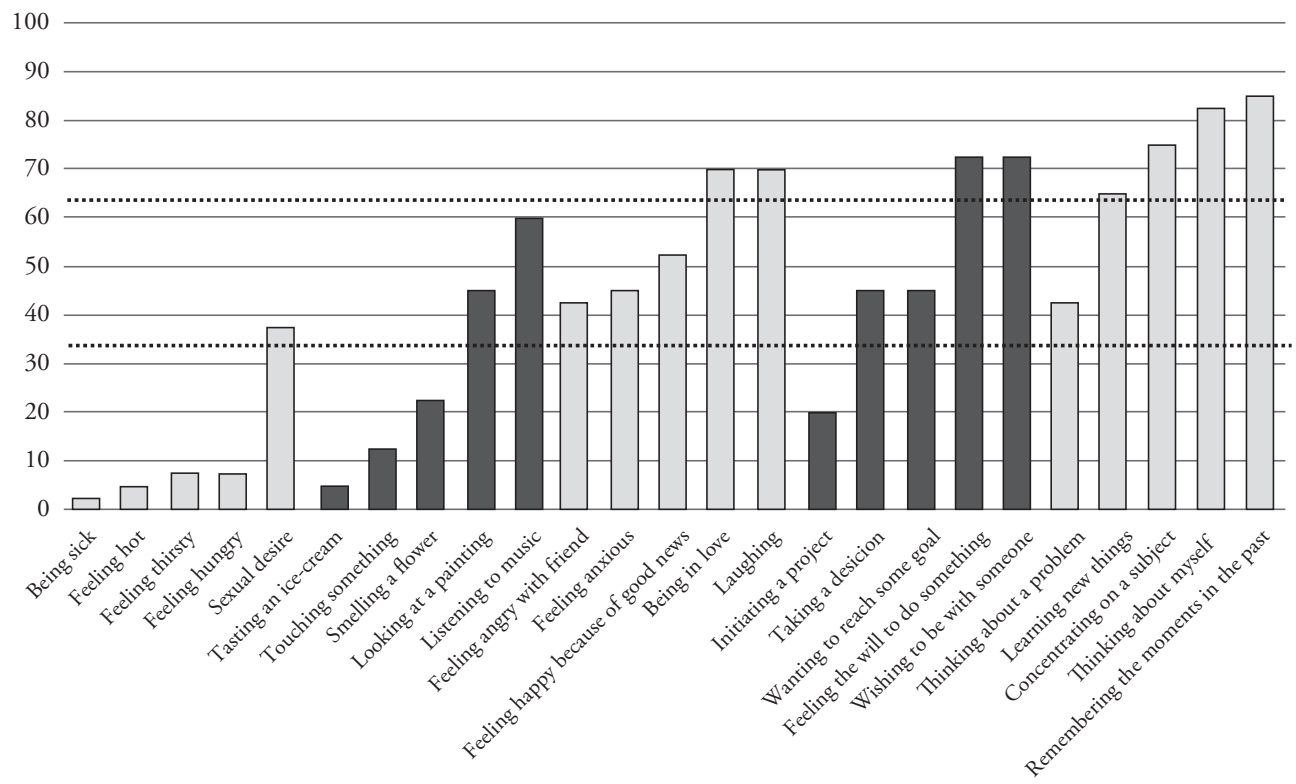

Figure 1. Percentage of continuity responses for the 25 items of the DBD Questionnaire (dotted lines correspond to the 95\% confidence interval around 50\%). 
(70\%, $p=0.017)$, Feeling the will to do something (73\%, $p=0.006)$, Laughing (70\%, $p=0.017)$, Wishing to be with someone (73\%, $p=0.006)$, Thinking about myself $(83 \%, p=0.000)$ and Remembering moments from the past $(85 \%, p=0.000)$. On the contrary, eight experiences were considered by significantly less than $50 \%$ of the sample as being possible to continue after death: Feeling hungry $(7 \%, p=0.000)$, Being sick $(2 \%, p=0.000)$, Initiating a project $(20 \%, p=0.000)$, Feeling thirsty $(7 \%, p=0.000)$, Touching something $(13 \%, p=0.000)$, Feeling hot $(5 \%, p=0.000)$, Smelling a flower $(23 \%, p=0.000)$, Tasting an ice-cream $(5 \%, p=0.000)$.

The results suggested that the experiences considered possible to continue after death belong exclusively to the epistemic, emotional and desire categories (with the exception of the Initiating a project experience), while psychobiological and perceptual experiences were not considered possible to continue in the afterlife.

Experiences Classification as More or Less Body Dependent. Figure 2 presents the percentage of responses in the higher values of the scale about degree of body dependence, for the 25 items of the DBD Questionnaire. Since the distribution of participants through the levels of the response scale was very

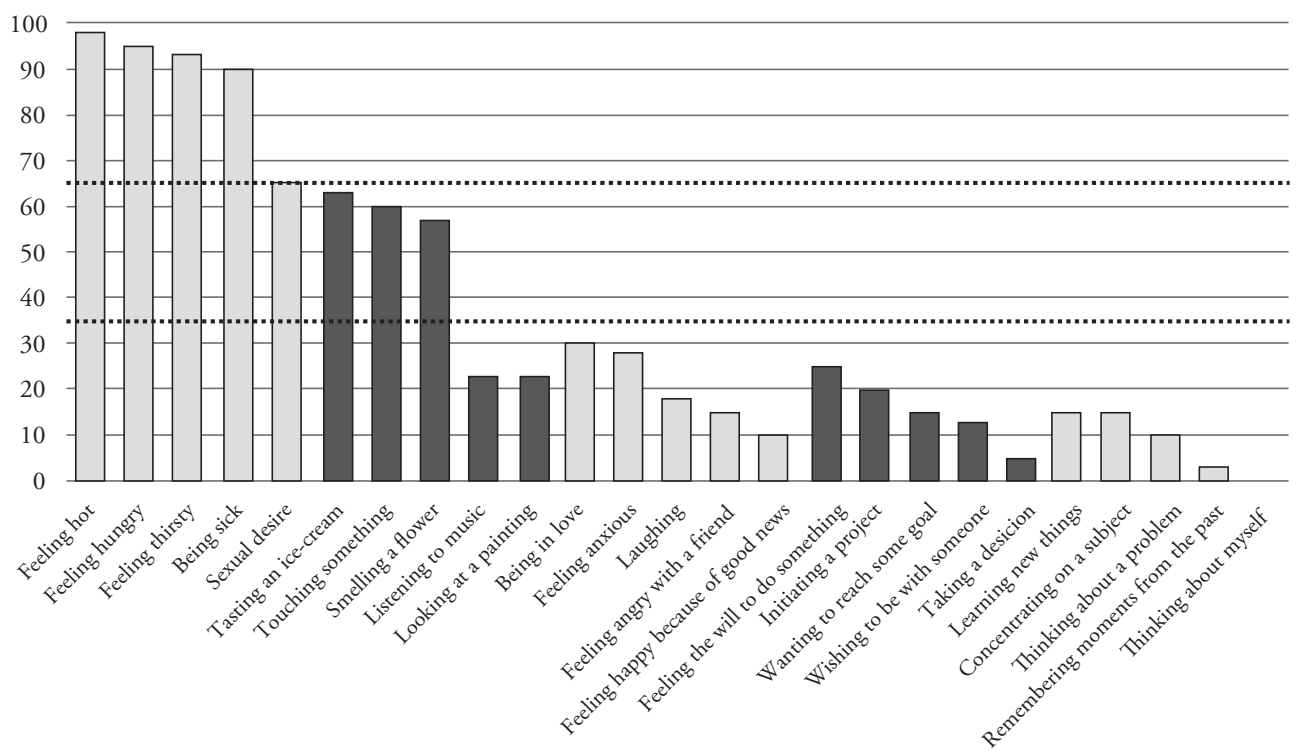

Figure 2. Percentage of dependent on the body responses for the 25 items of the DBD Questionnaire (dotted lines correspond to the 95\% confidence interval around 50\%). 
irregular, the original four-points scale was transformed into a dichotomous variable: (1) Independent on the body (totally independent to slightly dependent) and (2) Dependent on the body (moderately to totally dependent).

Using the binominal test, we found that only four out of the 25 experiences were considered as dependent on the body by significantly more than $50 \%$ of the sample: Feeling hungry ( $95 \%, p=0.000)$, Being sick $(90 \%, p=0.000)$, Feeling thirsty $(93 \%, p=0.000)$, Feeling hot $(98 \%, p=0.000)$. Test results also showed that only a small number of participants (significantly below $50 \%$ of the sample) considered the following experiences as dependent on the body: Listening to music $(23 \%, p=0.001)$, Looking at a painting $(10 \%, p=0.000)$, Feeling angry with a friend $(15 \%, p=0.000)$, Concentrating on a subject $(15 \%, p=0.000)$, Being in love $(30 \%, p=0.017)$, Learning new things $(15 \%$, $p=0.000)$, Initiating a project $(20 \%, p=0.000)$, Feeling the will to do something $(25 \%, p=0.002)$, Feeling happy because of good news $(10 \%, p=0.000)$, Laughing $(18 \%, p=0.000)$, Thinking about a problem $(10 \%, p=0.000)$, Making a decision $(5 \%, p=0.000)$, Wishing to be with someone $(13 \%, p=0.000)$, Thinking about myself $(0 \%, p=0.000)$, Remembering moments of the pass $(3 \%, p=0.000)$, Wanting to reach some goal $(15 \%, p=0.000)$, Feeling anxious $(28 \%, p=0.006)$. Finally, four experiences - Sexual desire $(65 \%, p=0.810)$, Touching something $(60 \%, p=0.268)$, Smelling a flower $(57 \%, p=0.430)$, or Tasting an ice-cream $(57 \%, p=0.154)$, did not reach consensus among participants related to their degree of body dependence.

\section{Association Between Continuation after Death and Degree of Body Dependence}

We found a significant negative correlation between continuation after death and degree of body dependence for the 25 items considered in the BDB Questionnaire (Spearman's rho $=-0.709, p=0.000$ ): experiences with higher percentages of positive continuity responses tend to be considered less dependent on the body. Figure 3 depicts the association between these two variables.

In Figure 3 we can identify six kinds of experiences: (1) experiences considered independent on the body and simultaneously possible to occur after death (circles; $N=8$ ); (2) experiences evaluated as independent on the body but regarded as not possible to continue after death (squares; $N=8$ ); (3) experiences evaluated as independent on the body and which continuity in the afterlife was implausible (diamond; $N=1$ ); (4) experiences evaluated as dependent on the body and considered non possible to occur after death (triangles; $N=4$ ); (5) experiences that did not reach consensus about their dependence on the body but significantly regarded as not possible to continue in the afterlife (stars; $N=3$ ); and (6) experiences reaching consensus neither about their degree of body dependence nor continuation after death (hexagon; $N=1$ ). 


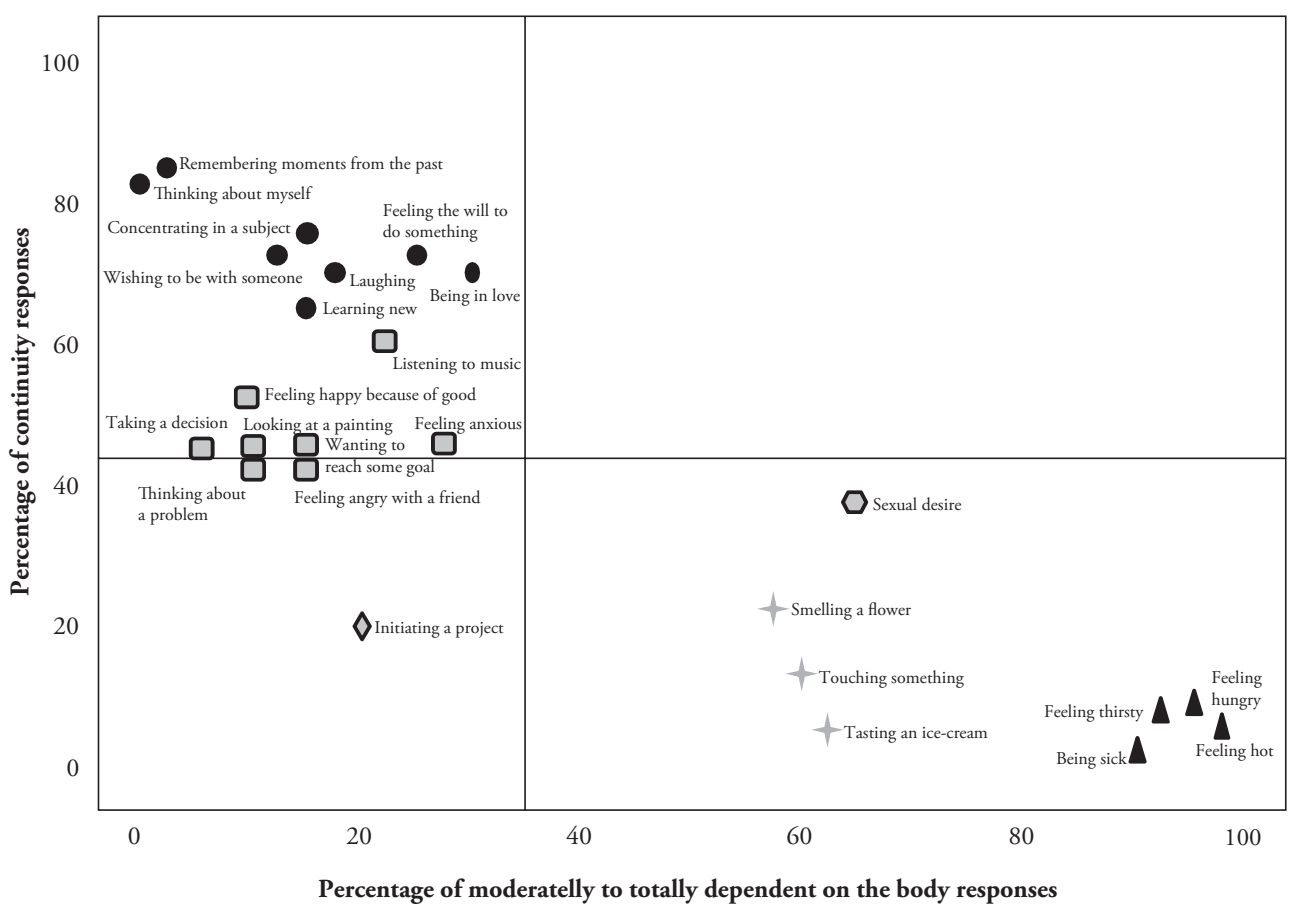

Figure 3. Association between continuation after death and degree of body dependence (horizontal and vertical lines represent the average percentage for each variable/axis).

No experience was simultaneously considered possible in the afterlife and dependent on the body. Apparently, independence of the body seems to be a criterion to consider an experience as possible to continue after death. However, the contrary might not hold true: experiences can be regarded as impossible to continue even when they are evaluated as independent on the body (squares are an example). These results suggest that independence of the body is not the only factor taken into account when deciding which experiences might be a part of the dead-I's existence.

The Effect of Explicit Beliefs in Afterlife in the Kinds of Experiences Considered Possible to Continue After Death

Due to their small dimensions, the five $A B$ groups were collapsed into two categories: one constituted by non-believers in an afterlife $(N=23)$ and the other constituted by all types of believers in any form of afterlife which assume the continuation of the I $(N=13)$. These two groups differ minimally in respect to the types of experiences they tend to consider possible after death. Only 
two experiences seem to have been evaluated differently by the groups: "Listening to music" (with a greater proportion of continuity responses from the believers group, $\chi^{2}=8.493, \mathrm{df}=1, p=0.004$ ) and "Thinking about myself" (with the opposite pattern, with non-believers giving a bigger percentage of positive responses than the believers group, $\left.\chi^{2}=5.143, \mathrm{df}=1, p=0.023\right)$.

\section{Discussion}

The hypothesized human tendency to imagine death from the perspective of a spectator (Sá-Nogueira Saraiva, 2003, 2012; see also Bauman, 1999; Freud, 1915/1957) was supported by the data collected during the interviews, since the majority of the sample imagined the state of being dead as a condition in which the I continues to be experienced. This trend was independent on the type of explicit $\mathrm{AB}$ and was present even in the Non-believers in the afterlife group.

Additionally, the hypothesis that the Subject-Self (I) remains after the death of the bodily parts of the Object-Self (Me) is also supported. Many participants (almost 50\%) have reported that they imagine their own death as something that they "observe", as if a part of themselves remained alive watching the burial of the body. A third of the participants (35\%) explicitly said that they felt it was impossible to imagine death as the complete absence of themselves, and some have even stated that they tend to believe in some form of afterlife since they cannot imagine the end of themselves: "(...) the disappearance of all that is around me is an aberration (...) that's why I think it could be possible to be something that survives without the body, because it's difficult imagining a consciousness disappearing." (Int. 39, male, 23 years old).

The preserved dead-I seems to be represented as similar to the one experienced during life. This result may indicate that while trying to imagine what life after death might be, people assume the continuation of their Subject-Self or I in accordance to the proposal of Sá-Nogueira Saraiva (2003). Qualitative and quantitative data have shown that the experiences attributed to the deadI were the epistemic, emotional, desire and perceptual (in the form of vision and hearing). This pattern occurred for all kinds of $A B$, including the participants who do not believe in any form of afterlife. Despite similarities, qualitative data suggests that specific cultural beliefs influence the way the dead-I is conceived. For instance, the belief in any form of afterlife seems to increase the attribution of experiences to the dead-I, except when $A B$ denies the permanence of the I after the death of the agent (Afterlife without an I).

We also found that the attribution of an experience to the dead-I appears to be related to its degree of body dependence, in accordance with predictions by 
Sá-Nogueira Saraiva (2003) and Pyysiäinen (2003). A negative correlation between judgements of afterlife continuity and body dependence was found for the 25 experiences analyzed, suggesting that the experiences with higher percentages of positive continuity responses tend to be considered less dependent on the body.

Judgements about the kinds of experiences the dead-I can have appear to be guided by implicit theories about the nature of the Self and its relation with the body, derived from the phenomenological experience of the I or SubjectSelf. The experience of the I as immaterial (Sá-Nogueira Saraiva, 2003) might contribute to the creation of an implicit association between the I and the experiences and mental states perceived as independent from the body.

Experiences which were evaluated as dependent on the body are not attributable to the dead-I. The contrary, however, might not hold true: experiences can be regarded as impossible to continue even when they are evaluated as independent on the body (e.g., "Making a decision"). This result suggests that the degree of body dependence is not the only factor taken into account when judging which experiences the dead-I might have. This may be because of cultural expectations about what is supposed to happen in a life after death. In fact, several participants stated that many items in the DBD Questionnaire described experiences incongruent with their general ideas about afterlife: "I don't see myself initiating projects over there, it would be a calm life, without work!" (Int. 37, female, 28 years old) or "I would be able to listen to sounds, but I don't think music would be possible to be heard on the afterlife. I would not have a radio out there!" (Int. 33, female, 26 years old). This may explain why so many experiences evaluated as independent on the body were not attributed to the dead-I, and why perceptual experiences (visual and auditory) were so much spontaneously attributed to the dead-I during the interview but did not reach a significant consensus when their afterlife plausibility was evaluated with the DBD Questionnaire. Future studies should address this drawback, using this information to guide the construction of more adequate items.

The simulation constraint hypothesis suggested by Bering (2002) is not supported by our data. Although emotional, epistemic and desire/agency experiences were among the most often attributed to the dead-I, and participants in our sample referred visual and auditory experiences as possible in the afterlife. The interview data revealed that the spontaneous attribution of visual experiences to the dead-I is even more frequent than the attribution of epistemic, emotional and desire/agency experiences. If, as the simulation constraint hypothesis suggests, the difficulty of imagining the absence of certain mental states were the fundamental criteria involved in the determination of the types of experiences the dead-I can have, visual experiences should not be attributable to the dead-I, since Bering (2002) considers them as EIA states. 
Interestingly, in Bering's factorial analysis of the attributed experiences, perceptual experiences clustered together in the same factor with the DIA states, and not, as the author expected, in the same factor as the EIA states.

Our results suggest that vision and hearing are evaluated differently from the other sensorial modalities, and associated with the dead-I in the same or even higher percentage than epistemic, emotional and desire/agency experiences. In fact, the degree of body dependence evaluations of these two kinds of experience is closer to the evaluations of epistemic, emotional and desire/ agency experiences than the other perceptual experiences in the DBD Questionnaire. In the light of the data collected in this study, it makes sense that visual and auditory experiences should appear together with the DIA experiences as conceived by Bering (2002), and not with other perceptual experiences.

Since Bering's (2002) study focused on the representation of dead agents, and our study is about the representation of one's own death, the different results about perceptual experiences might be due to the different nature of the tasks proposed in each study. Future research should be able to clarify if the representation of dead agents and the representation of one's own dead-I are tasks involving the same cognitive mechanisms.

The association of visual and auditory experiences to the dead-I cannot be explained by a simulational constraint like the one suggested by Bering (2002, 2006), but is compatible with the hypothesis of Sá-Nogueira Saraiva (2003) that assumes that the notion of the survival of the soul after death results from the impossibility of eliminating the experience of the I as a subject of experience and centre of agency (see also Sá-Nogueira Saraiva, 2012). If the dead-I is represented as a continuation of the I (Subject-Self) experienced in life, it will be characterized by important aspects of the phenomenological experience of being an I, namely mental images and internal dialogue, so frequent in our internal spaces of representation. The capacity to "see and hear mentally" is, therefore, inherent to that experience, contributing to their dissociation from the body in as much as the body is the object part of the I. Additionally, vision and hearing are also the dominant sensorial modalities in humans and our sense of agency in the world might be intensely related to the possibility of perceiving that world through these senses. This association between the I and perception could also explain why ethnographic data show that ghosts are rarely or never represented as blind or deaf (Whitehouse, 2006).

The responses of some participants appear to support the idea that the capacity to perceive the world around us could be felt as an integrant part of the I, relatively independent on the body: "For me, vision... I forget it comes 
from the body, it feels like it comes from me, it's probably an illusion, but it is what I feel, I feel that it is mine, that it comes from within, and it is one of the major ways to construct and know the world around me" (Int. 39, male, 23 years old). "[when imagining myself dead] I see the darkness, as if I was locked in a room without any light. I felt that some auditory sense might still exist. If I think, I speak to myself and I can, at least, still hear myself." (Int. 26, male, 24 years old).

Studies with blind or deaf subjects could help clarify the eventual role of other sensorial modalities in the representation of the dead-I.

\section{Immortality of the Soul as an Intuitive Religious Concept}

The data collected in this study suggest that the experience and implicit theorization of the Self appears to be of consequence to the representation of one's own death. The necessity of including the concept of the Self in theoretical accounts of religious phenomena has been recognized some years ago (Bering, 2006). Our results suggest that the phenomenology of the Self should be taken into account when investigating religious phenomena like afterlife beliefs.

The representation of one's own death is inevitably constrained by the experience of the Self. In fact, the emergence of objective self-awareness (Duval and Wicklund, 1972), i.e., the capacity to be aware of themselves as objects in the world, appears to have allowed human individuals to be aware of their own death (Silvia, 2001). At the same time, the impossibility of eliminating the experience of the I (Sá-Nogueira Saraiva, 2003), while imagining its own death, may have made humans prone to distinguish two kinds of Self: one that is identified with the body that dies and with the external and social aspects of the Self, that James (1890) called "Me", and is denominated as Object-Self by Sá-Nogueira Saraiva (2003), and another, felt as immaterial and somehow disconnected from the body, that seems to be capable of surviving physical death (the I or Subject-Self). Sá-Nogueira Saraiva (2003) advanced that the classical distinction between two types of souls in ethnographic literature ego/free soul and life soul (Hultkrantz, 1953/1997, 1967/1979; Bremmer, 1983/1993) - could be the cultural elaboration of these two perspectives of the Self experienced by humans - Subject-Self (I) and Object-Self (Me), respectively. This suggestion is further supported by the many cases in which a person (the Subject-Self/ I) can leave the body or assume different bodies and by the frequent metaphor of the body as the soul's horse (see references in Sá-Nogueira Saraiva, 2012 and a major review in Eliade, 1951/1968).

This proposal could explain the "fundamental paradox" identified by Morin (1970): at the same time that Humans are capable of understanding that life 
is finite, they tend to consider the continuation of themselves after death as plausible, since a part of the Self is experienced as potentially immortal.

If the immortality of the I is phenomenologically plausible, as we are arguing, then ideas about the continuation of mental processes after death could be generated even in the absence of contact with explicit afterlife beliefs. The notion of an immortal soul could be an intuitive religious concept, potentially emergent in human minds despite specific culture indoctrination. Afterlife beliefs could have had their origin in these intuitive notions, their specificities being the result of an intricate and long process of cultural elaboration.

We are aware of the difficulty in studying psychological origins of cultural phenomena. Human children receive explicit cultural information from a very early age, and it is difficult to know if ideas about the preservation of the I after death are present before contact with cultural explicit notions of immortal souls or ghosts. We think it is reasonable to assume that although contact with afterlife cultural notions occurs before or concomitantly with the first thoughts about death, the success of transmission of cultural afterlife beliefs is dependent on the already existing latent tendency to intuitively conceive the I in a way that favours the attribution of certain mental processes and experiences to the dead. Without this predisposition, cultural ideas about the afterlife would not be meaningful for people contacting with them for the first time, and would probably be discarded as nonsense. Afterlife beliefs are "sticky" ideas (Boyer, 2003) precisely because they resonate with our intuitions about the nature and characteristics of the Self and Body. The fact that developmental studies (Bering and Bjorklund, 2004; Bering et al., 2005) showed that the tendency to represent dead agents as capable of mental states might be present since infancy is clearly relevant in this context.

Although we do not assume that immortal souls are innate ideas, completely independent from cultural learned information, we think our data and previously collected data (Bering, 2002; Bering and Bjorklund, 2004; Bering et al., 2005) are evidences favoring the possibility that non-reflective beliefs (Barrett, 2003) in the continuation of the experience of the I and of various mental states after death are potentially present in human minds.

Concerning the possible direct evolutionary origins of intuitive afterlife concepts, Sá-Nogueira Saraiva (2012) suggests they emerged as a by-product of human self-awareness and theory of mind typical functioning. We consider it is premature to assume the possibility of an evolved religious psychological system (Bering, 2006), since the reproductive advantage of believing in an immortal soul or agent is not obvious. The extensive commentaries to Bering's (2006) article emphasize the need for caution in this regard. 


\section{Future Directions}

The proposed hypothesis that the immortality of the soul is an intuitive or non-reflective religious idea makes sense in the light of our data, but needs to be addressed by additional studies before it can be adequately tested.

To start, our results were obtained from a very specific sample, so we are not confident about their generalization to the entire adult population. The constitution of a larger and more heterogeneous sample, in terms of age, academic habilitations and religious beliefs, might offer more generalizable results.

The controversy in the literature about the origin of afterlife beliefs - cognitive predisposition (Bering, 2002, 2006; Bering and Bjorklund, 2004; Bering et al., 2005) or cultural learning (Harris and Astuti, 2006; Astuti and Harris, 2008) - has been sustained by contradictory findings in developmental as well as cultural data and accentuates the need for more cross-cultural and developmental studies in this area.

If the phenomenology and representation of the Self contributes to the emergence of intuitive afterlife concepts that constitute psychological origins of afterlife beliefs shared by humans, we should be able to find some regularity in Self-experience and Self's implicit theorization across cultures.

A large body of evidence demonstrates that the Self is a cognitive and phenomenological entity recognized and discussed in various cultural contexts (Strawson, 2009). The rich descriptions of, and lively debates about, the concept of soul in all complex cultures (see Martin and Barresi, 2006 for the occidental tradition and Watson, 2006 for the oriental tradition), as well as the theorization about Ego and Free souls in simpler cultures (Hultkrantz, 1953/1997, 1967/1979), are evidence of the prevalence of the Self. In fact, it has been argued that language could not exist without a sense of self because the perpendicular pronoun and the first person declensions are, by definition, self-referential (Sá-Nogueira Saraiva, 2012; Sá-Saraiva and Sá-Saraiva, in press). It has been argued that the Self has many precursors in non human motile animals (Sá-Nogueira Saraiva, 2012), and Damásio (2010) has reinforced this view by claiming that even consciousness could not have developed in humans without the previous emergence of a sense of Self. Also, theory of mind appears to be a universal mechanism in the human species (Wellman et al., 2001; Quintanilla and Sarriá, 2003; Oberle, 2009) dating from at least 500000 years ago (Sá-Saraiva and Sá-Saraiva, in press), or even earlier (Shipton, 2010), and theory of mind is not possible without a self-experience. We therefore suggest that there is a good chance of the Self structure and experience being universal, despite already recognized cultural specificities (Markus and Kitayama, 1991; Chentsova-Dutton and Tsai, 2010). 
Understanding the way in which people of various cultural contexts experience and implicitly represent their selves might be an important step to understand the recurrence and prevalence of the belief in an immortal soul that might live after bodily death. Afterlife beliefs and the related questions of the Self therefore seem to be a window into future studies of religion and cognition.

\section{Acknowledgement}

Support for this research project was provided by a $\mathrm{PhD}$ thesis grant awarded to the first author by Fundação para a Ciência e Tecnologia (SFRH/ $\mathrm{BD} / 27307 / 2006)$.

\section{References}

Astuti, R. and Harris, P. L. (2008). Understanding mortality and the life of the ancestors in rural Madagascar. Cognitive Science 32, 713-740.

Barrett, J. L. (2003). Epidemiological and nativist accounts in the cognitive study of culture: A commentary on Pyysiäinen's innate fear of Bering's ghosts. Journal of Cognition and Culture 3, 226-232.

Bauman, Z. (1992). Mortality, Immortality and Other life Strategies. Stanford University Press, Stanford, CA.

Bering, J. M. (2002). Intuitive conceptions of dead agents' minds: The natural foundations of afterlife beliefs as phenomenological boundary. Journal of Cognition and Culture 2, 263-308.

- (2006). The folk psychology of souls. Behavioral and Brain Sciences 29, 453-498.

Bering, J. M. and Bjorklund, D. F. (2004). The natural emergence of reasoning about the afterlife as a developmental regularity. Developmental Psychology 40, 217-233.

Bering, J. M., Blasi, C. H. and Bjorklund, D. F. (2005). The development of "afterlife" beliefs in religiously and secularly schooled children. British Journal of Developmental Psychology 23, 587-607.

Birket-Smith, K. (1955). Histoire de la Civilisation: caractéristiques et conditions du développement des sociétés rustiques et préindustrielles $d u$ passé et $d u$ present. Payot, Paris.

Bloom, P. (2004). Descartes' baby: How the science of child development explains what makes us buman Basic Books, New York, NY.

- (2007). Religion is Natural. Developmental Science 10, 147-151.

Boyer, P. (1994). The naturalness of religious ideas: a cognitive theory of religion. University of California Press, Berkeley, CA.

. (2003). Are ghost concepts "Intuitive", "Endemic" and "Innate"? Journal of Cognition and Culture 3, 233-243.

Bremmer, J. (1983/1993). The early Greek concept of soul. Mythos Series. Princeton University Press, Princeton, NJ.

Brown, D.E. (1991). Human Universals. McGraw-Hill, New York, NY.

Chentsova-Dutton, Y. E. and Tsai, J. L. (2010). Self-focused attention and emotional reactivity: The role of culture. Journal of Personality and Social Psychology 98, 507-519. 
Damásio, A. (2010). O Livro da Consciência: A construção do cérebro consciente. Círculo de Leitores, Lisbon.

Duval, T. S. and Wicklund, R. A. (1972). A theory of objective self awareness. Academic Press, New York, NY.

Eliade, M. (1951/1968). Le chamanisme et les techniques archaïques de l'extase, 2nd edn. Payot, Paris.

Freud, S. (1915/1957). "Thoughts for the Times on War and Death.” In Strachey, J. (Ed.), The Standard Edition of the Complete Psychological Works of Sigmund Freud, Volume 14, pp. 275-302. The Hogarth Press, London.

Goldman, A. (1992). In defence of simulation theory. Mind and Language 7, 104-119.

(1993). The psychology of folk psychology. Behavioral and Brain Sciences 16, 15-28.

Harris, P. L. (1992). From simulation to folk psychology: The case for development. Mind and Language 7, 120-144.

Harris, P. L. and Astuti, R. (2006). Learning that there is life after death. Behavioral and Brain Sciences 29, 475-476.

Hultkrantz, A. (1953/1997). Conceptions of the Soul among north american Indians / Soul and native Americans. Spring Publications, Woodstock, NY.

- (1967/1979). The Religions of the American Indians. University of California Press, Berkeley, CA.

James, W. (1890). The principles of psychology. Dover Press, New York, NY.

Markus, H. R. and Kitayama, S. (1991). Culture and the self: Implications for cognition, emotion, and motivation. Psychological Review 98, 224-253.

Martin, R. and Barresi, J. (2006). The rise and fall of Soul and Self: An intellectual history of personal identity. Columbia University Press, New York, NY.

Mason, J. (1998). Qualitative Researching. Sage, London.

Miles, M. B. and Huberman, A. M. (1994). Qualitative data analysis, 2nd Ed. Sage, London.

Morin, E. (1970). O Homem e a Morte, 2nd edn. Publicaçôes Europa-América, Mem Martins.

Obayashi, H. (1992). Introduction. In Obayashi, H. (Ed.), Death and Afterlife: Perspectives of World Religions, pp. ix-xxii. Praeger, Westport, CT.

Oberle, E. (2009). The development of theory of mind reasoning in Micronesian children. Journal of Cognition and Culture 9, 39-56.

Pinker, S. (2002). The blank slate: The modern denial of human nature. Penguin Books, London.

Pollio, H. R., Henley, T. and Thompson, C. B. (1997/2006). The Phenomenology of Everyday Life. Cambridge University Press, New York, NY.

Pyysiäinen, I. (2003). On the "Innateness of Religion: A Comment on Bering". Journal of Cognition and Culture, 3, 218-225.

Quintannilla, L. and Sarriá, E. (2003). Realismo, Animismo y Teoría de la Mente: características culturales y universales del conocimiento mental. Estudios de Psicologia 24, 313-323.

de Sá-Nogueira Saraiva, R. (2003). Mundos Animais, Universos Humanos. Fundação Calouste Gulbenkian, Lisbon.

- (2012). Evolutionary Psychology of the I and Me. Revista Portuguesa de Filosofia 66, 945-962.

Sá-Saraiva, R. de and Sá-Saraiva, A.I. (in press). On the Acheulean Origin of Mind and Language. Theoria et Historia Scientiarum.

Shipton, C. (2010). Imitation and shared intentionality in the Acheulean. Cambridge Archaeological Journal 20, 197-210.

Silvia, P. J. (2001). Nothing or the Opposite: Inserting Terror Management and Objective SelfAwareness. European Journal of Personality 15, 73-82.

Sperber, D. (1996). Explaining culture: a naturalistic approach. Blackwell, Oxford. 
Strawson, G. (2009). Selves. Oxford University Press, New York, NY.

Thomas, L.-V. (1975). Anthropologie de la mort. Payot, Paris.

Watson, A. (2006). The Self's Awareness of Itself: Bhatta Ramakantha's Arguments against the Buddhist Doctrine of No-Self. De Nobili, Vienna.

Wellman, H. M., Cross, D. and Watson, J. (2001). Meta-Analysis of Theory-of-Mind Development: The truth about False Belief. Child Development 72, 655-684.

Whitehouse, H. (2006). Reasoning about dead agents: A cross-cultural perspective. Commentary/Bering: the folk psychology of souls. Behavioral and Brain Sciences 29, 485.

\section{Appendix A}

\section{Script for the Semi-Structured Interview}

Theme 1

Experience of imagining one's own death

1.1) I would like to ask you to make a little imagination exercise. Concentrate and try to imagine what it would be like to die and to be dead. Close your eyes, take a deep breath and concentrate on the task. Try to imagine this without worrying about the logical sense of your fantasy or what might be right or wrong. Tell me the first images and thoughts that you had during the exercise.

1.2) What have you imagined?

1.3) While imagining yourself dead, did you felt as an observer or a participant? (to use only if not mentioned spontaneously by the interviewees)

1.4) Was it difficult to imagine your own death? What difficulties come up?

1.5) Was there anything that you imagined that seemed strange or contradictory?

Theme 2

Representation of the dead-I

2.1 If participants response about the imagination experience reports a continuation of the I after death, without giving enough information about the characteristics and kinds of experiences the dead-I might have (try to follow what is spontaneously referred by the interviewees, in order to avoid influencing too much their representation of the dead-I):

2.1.1) When you imagined yourself dead, what happened to your mind, to your conscious experience? Did you imagine that it ended when your body stopped functioning?

2.1.2) Having in mind the way in which you imagined yourself as a dead person, what experiences made sense that you could continue to have in that life after death? (according to the type of experiences mentioned, you should pose more specific questions and try to understand if epistemic, emotional, desire/agency, psychobiological and perceptual experiences might continue after death).

2.2 If participants' imagination of the dead state does not hold a continuation of existence of the I after death:

2.2.1) If you had to imagine a life after death, independently of what you belief will happen after you die, how would it be?

2.2.2) What kind of experiences could you have in that afterlife? 
Theme 3

Identification and characterization of religious beliefs of participants, mainly their conceptions about what happens after death to the body and self.

3.1) Do you believe in any form of life after death? Can you explain me a little bit more what you actually believe will happen when you die?

3.2) How would you define you religious beliefs?

\section{Appendix B}

\section{DBD Questionnaire}

Please, evaluate the following experiences in respect to the degree that you feel them as more or less dependent on the body. Try to ignore your scientific knowledge about this matter and respond only according to the way you feel each experience in your daily life. Use the following scale to evaluate each of the experiences presented: 1-Totally independent on the body; 2- Slightly dependent on the body; 3-Moderatelly dependent on the body; 4-Totally dependent on the body

Experience

(Portuguese version)

1. Sentir fome

2. Ouvir uma música

3. Estar zangado(a) com um amigo

4. Concentrar-se num assunto

5. Estar doente

6. Estar apaixonado por alguém

7. Aprender coisas novas

8. Iniciar um projecto

9. Vontade de fazer uma coisa

10. Desejo sexual

11. Observar um quadro

12. Ficar feliz ao receber uma boa noticia

13. Rir

14. Pensar sobre um problema a resolver

15. Tomar uma decisão

16. Desejar estar com alguém

17. Sentir sede

18. Tocar numa coisa

19. Pensar sobre si próprio

20. Recordar momentos do passado

21. Querer alcançar certo objectivo

22. Sentir calor

23. Cheirar uma flor

24. Saborear um gelado

25. Sentir ansiedade
Degree of body dependence

(English version)

Feeling hungry

Listening to music

Feeling angry with a friend

Concentrating on a subject

Being sick

Being in love

Learning new things

Initiating a project

$\begin{array}{llll}1 & 2 & 3 & 4\end{array}$

$\begin{array}{llll}1 & 2 & 3 & 4\end{array}$

$\begin{array}{llll}1 & 2 & 3 & 4\end{array}$

$\begin{array}{llll}1 & 2 & 3 & 4\end{array}$

$\begin{array}{llll}1 & 2 & 3 & 4\end{array}$

$\begin{array}{llll}1 & 2 & 3 & 4\end{array}$

$\begin{array}{llll}1 & 2 & 3 & 4\end{array}$

$\begin{array}{llll}1 & 2 & 3 & 4\end{array}$

Feeling the will to do something $\quad \begin{array}{lllll}1 & 2 & 3 & 4\end{array}$

$\begin{array}{lllll}\text { Sexual desire } & 1 & 2 & 3 & 4\end{array}$

$\begin{array}{lllll}\text { Looking at a painting } & 1 & 2 & 3 & 4\end{array}$

Feeling happy because of good $\quad \begin{array}{llll}1 & 2 & 3 & 4\end{array}$ news

Laughing

$\begin{array}{llll}1 & 2 & 3 & 4\end{array}$

$\begin{array}{lllll}\text { Thinking about a problem } & 1 & 2 & 3 & 4\end{array}$

$\begin{array}{lllll}\text { Taking a decision } & 1 & 2 & 3 & 4\end{array}$

$\begin{array}{lllll}\text { Wishing to be with someone } & 1 & 2 & 3 & 4\end{array}$

$\begin{array}{lllll}\text { Feeling thirsty } & 1 & 2 & 3 & 4\end{array}$

$\begin{array}{lllll}\text { Touching something } & 1 & 2 & 3 & 4\end{array}$

$\begin{array}{lllll}\text { Thinking about myself } & 1 & 2 & 3 & 4\end{array}$

$\begin{array}{lllll}\text { Remembering moments from } & 1 & 2 & 3 & 4\end{array}$ the past

$\begin{array}{lllll}\text { Wanting to reach some goal } & 1 & 2 & 3 & 4\end{array}$

$\begin{array}{lllll}\text { Feeling hot } & 1 & 2 & 3 & 4\end{array}$

$\begin{array}{lllll}\text { Smelling a flower } & 1 & 2 & 3 & 4\end{array}$

$\begin{array}{lllll}\text { Tasting an ice-cream } & 1 & 2 & 3 & 4\end{array}$

$\begin{array}{lllll}\text { Feeling anxious } & 1 & 2 & 3 & 4\end{array}$ 
Now please, signal the experiences of this list that you think might continue after death, according to what you imagined a while ago. Please, try to separate your beliefs about the afterlife from what you imagined. Some experiences might make sense in light of the imagined scenes that do not correspond to your beliefs. Focus in what you imagined and not necessarily in what you believe.

Note: The items of the DBD questionnaire were classified into the following categories: Psychobiological experiences (1. Feeling hungry; 5. Feeling ill; 10. Sexual desire; 17. Feeling thirsty; 22. Feeling hot), Perceptual Experiences (2. Listen to music; 11. Observing a painting; 18. Touching something; 23. Smelling a flower; 24. Tasting an ice-cream), Emotional Experiences (3. Feeling angry with a friend; 6 . Being in love; 12 . Feeling happy for receiving good news; 13 . Laughing; 25. Feeling anxious) and Desirelagency experiences (8. Initiating a project; 9. Feeling the will to do something; 15. Making a decision; 16. Desiring to be with someone; 21. Wanting to reach some goal).

\section{Appendix C}

\section{Examples of Answers Coded in Each Node}

A) Explicit beliefs in the afterlife

A1) Non-belief in the afterlife

"I think that we die and that's it (...) what remains here is the works you did in life. I do not believe in any form of life after death. " (Int. 17, female, 22 years old)

A2) Afterlife possible but uncertain

"Death doesn't make sense (...) Because of what it is to be aware of oneself, I am not talking about thoughts in themselves but the consciousness behind those thoughts. The sensation of being alive, the sensation of existing should not end because we stop breathing and the organs shut down, it doesn't make sense! It just doesn't make sense, so I tend to think there must be some form of survival of consciousness." (Int. 40, male, 23 years old)

A3) Afterlife in another dimension

"I imagine a place apart from here. My Catholic education makes me imagine that it's somewhere above the earth, from where people can see their relatives that are still alive." (Int. 37, female, 28 years old)

A4) Afterlife without an I

"I think that it wouldn't be an identity, because identity is connected to specificity and I think that an existence after death would be one of connection to the absolute and not to specificity. Me, as an individual, will probably end." (Int. 10, male, 24 years old)

A5) Afterlife undefined

"There is something, but I don't know how it will be." (Int. 38,female, 26 years old)

B) Experience of imagination of one's own death

B1) Continuation of the I

"I am surrounded by darkness and I'm aware of that darkness and of myself." (Int. 40, male, 23 years old) 
B2) Observation of one's own death

"The only thing I see is myself dead (...) I see myself dead on the floor and I am already out of my body looking for my dead body from above." (Int. 14, female, 27 years old)

B3) The I that continues is connected to the body

"I saw them above me, like I was in my body, inside the coffin and was observing them but they did not notice that." (Int. 5, male, 25 years old)

B4) Impossibility of imagining death as a total end

"I cannot imagine myself dead! I can imagine that I'm dead and everyone is here around me grieving and crying, but I am observing, like they could not realize that I'm with my eyes open looking at them." (Int. 5, male, 25 years old)

B5) Absence of the I

"I tried to imagine what it would be like if a subject observing reality ceased to exist. A sensation of emptiness of inexistence." (Int. 30, male, 27 years old)

B6) Imagination of the moment before dying

"I did not imagined myself dead, it was more the process of dying. I was sick in a hospital or something like that." (Int. 36, female, 30 years old)

C) Implicit representation of the Dead-I

C1) Types of implicit representation of the dead-I

C1.1) Dead-I similar to the one held in life

"Without a body but with consciousness, memories from the past, capacity to feel and having sensations that although physical, would remain now as sensations of consciousness, like if consciousness kept the sensorial characteristics of the body." (Int. 39 , male, 23 years old)

C1.2) Dead-I distinct from the one held in life

"It would be like being connected to everything around us. The feeling of belonging, of not being a separated individual. A state after death would be of fusion, not separation as in life." (Int. 13, male, 22 years old)

C1.3) Dead-I non-existent

"I just imagined the absence of consciousness, I tried to imagine the unconsciousness of myself (...) I cannot imagine any kind of life after death, it doesn't make sense." (Int. 8, female, 26 years old)

C2) Experiences of the dead-I

C2.1) Psychobiological

"I imagine that things like feeling hungry, having to go to the bathroom, taking a bath would not be present, since the body ceases to exist." (Int. 1, female, 26 years old)

C2.2) Perceptual

"Hearing I think I would not be able, the body is inanimate! But curiously, I imagined I still was able to see!" (Int. 23, male, 26 years old)

C2.3) Emotional

"I imagine myself still able to have emotions and feelings." (Int. 26, male, 24 years old)

C2.4) Epistemic

"It would be just a more mental activity, remembering and thinking, and stuff like that." (Int. 24, male, 24 years old).

C2.5) Desire/agency

"I would still want to be near the persons I like." (Int. 35, male, 20 years old) 
